\title{
BUILDING CAPACITY FOR DEVELOPING STATISTICAL LITERACY IN A DEVELOPING COUNTRY: LESSONS LEARNED FROM AN INTERVENTION
}

\author{
DELIA NORTH \\ University of KwaZulu-Natal, South Africa \\ northd@ukzn.ac.za \\ IDDO GAL \\ University of Haifa, Israel \\ iddo@research.haifa.ac.il \\ TEMESGEN ZEWOTIR \\ University of KwaZulu-Natal, South Africa \\ zewotir@ukzn.ac.za
}

\begin{abstract}
This paper aims to contribute to the emerging literature on capacity-building in statistics education by examining issues pertaining to the readiness of teachers in a developing country to teach basic statistical topics. The paper reflects on challenges and barriers to building statistics capacity at grass-roots level in a developing country, based in part on lessons learnt from the design of an in-service intervention for teachers in South Africa, and on illustrative data about teachers' attitudes, collected as part of this intervention. The paper reflects on implications for future design of interventions, as well as on research needs that can inform future capacity-building in statistics education in developing countries.
\end{abstract}

Keywords: Statistics education research; South Africa; Teacher knowledge; Self-efficacy; Attitudes

\section{INTRODUCTION}

Statistical topics have been introduced during school education in many countries over the last few decades. Statistics is seen as a vital topic since future citizens in all countries should be able to orient themselves in a data-driven world and hence possess skills and understanding of issues in data collection, organization, analysis or interpretation (Zewotir \& North, 2011). The need to attend to statistical knowledge has been recognized around the world and many countries have introduced statistics or data analysis (or related topics under labels such as data handling or stochastics or chance) as a topic in national curricula for numerous grade levels. Yet, this does not mean that statistics is actually being taught, or taught well, to all students. In most countries, mathematics teachers are tasked with teaching statistics, but they do not necessarily have the knowledge required to do so (Stohl, 2005). Further, the literature has focused mainly on issues in improving statistics education among teachers and learners from developed countries. Relatively little is known about attempts to build capacity for statistics education in developing countries, or about factors affecting the quality of statistics education in such countries.

With the above in mind, this paper aims to contribute to the statistics education literature by examining three issues. First, we reflect on key issues in developing educational capacity in statistics education in the context of a developing country, using South Africa as a particular case study. Second, we describe a brief intervention introduced in South Africa (the

Statistics Education Research Journal, 13(2), 15-27, http://iase-web.org/Publications.php?p=SERJ (C) International Association for Statistical Education (IASE/ISI), November, 2014 
'maths4stats Lecture Series') to provide mathematics teachers with some knowledge about teaching statistics, and examine and reflect upon selected data that emerged out of an evaluation process that accompanied this program. In this way, we illustrate some of the many issues involved in developing and studying statistics education in the context of a developing country. Lastly, we discuss implications for future research needs and the role of collaborations in improving capacity in developing countries in general, and in South Africa in particular. Thus, this paper is not positioned as a standard research report, but aims to inform a muchneeded discussion about research needs and research directions, using field-based experiences of the authors and some emerging data as a basis for critical reflection.

\section{INFUSING STATISTICS EDUCATION IN DEVELOPING COUNTRIES}

\subsection{GENERAL EDUCATION ISSUES}

In thinking about ways to improve the teaching and learning of mathematics and science in schools, the literature naturally focuses on ways to develop or change teachers' knowledge, attitudes, and classroom practices, either through pre-service preparation or in-service professional development. However, most of the research literature that relates to teacher training or professional development in statistics comes mainly from western countries which are among the so-called 'developed' countries. Thus, there is little attention to the realities of developing countries in this regard. Yet, the professional literature on education systems has long recognized that there are marked differences between developed and developing countries which have important ramifications for teacher education or professional development, including in statistics education.

Research regarding characteristics of education systems in developing countries is published by numerous sources, including, but not limited to, UNESCO and World Bank and many independent research groups. The emerging picture (see, e.g., Glewwe, Hanushek, Humpage, \& Ravina, 2011; UNESCO, 2014) points to several perennial problems, such as lack of adequate preschool education and low achievement of basic skills in primary education, implying that many children continue into later school years without adequate preparation and are thus not ready to fully cope with learning of more advanced subjects. These are followed by low enrollment in schools and high dropout levels.

Further, teacher quality and availability are also particularly common problems in developing countries, with many teachers lacking formal preparation in teaching in general or in specific subject areas, and with shortages of teachers and school buildings or supplies. UNESCO's most-recent Global Monitoring Report (UNESCO, 2014) stated that "In around a third of countries, less than $75 \%$ of primary school teachers are trained according to national standards. And in a third of countries, the challenge of training existing teachers is worse than that of recruiting and training new teachers." (p. 5)

High pupil/teacher ratios is another issue in developing countries. The UNESCO 2014 report claims that average pupil/teacher ratios have hardly changed at the pre-primary, primary and secondary levels over the last 15 years:

In sub-Saharan Africa, with teacher recruitment lagging behind growth in enrolment, ratios are the highest in the world at the pre-primary and primary levels. Of the 162 countries with data in 2011, 23 countries in sub-Saharan Africa had a pupil/teacher ratio in primary education exceeding 40:1. (p. 5)

These and other issues are often linked in the literature to low expenditure on education (calculated as percentage of GDP) compared to the situation in developing countries (Glewwe $\&$ Kremer, 2005). Further, the educational systems of many developing countries are in a state of transformation as governments attempt to overcome legacies of former (often colonial) systems, while balancing risks and opportunities associated with their independence. Accordingly, school curricula are being transformed in these countries, with a need to accommodate worldwide educational trends and innovations in education, while taking into account local traditions and available systems and resources. 
When examining specifically the situation of teachers who teach mathematics at the primary or secondary levels in developing countries, further issues emerge that are unique to or more strongly evident in developing countries. A UNESCO (2012) report regarding the teaching of mathematics in primary education in developing countries has highlighted, among other things, the decline in teachers who are interested in and actually engage in learning mathematics at the university level, thus causing a shortage of teachers with subject matter knowledge. Further, in many countries the quality of teacher education is far from satisfactory, even when there is no problem with the number of available teachers, affecting the extent to which teachers are well trained mathematically, didactically and pedagogically. As the report (UNESCO, 2012) argues:

Most basic education teachers, in particular in the beginning classes but in all classes in a number of countries, have experienced difficulties in their own mathematics education and have a negative image of the discipline. They are often general-purpose teachers and their credit hours of science education and, above all, mathematics education account for only a fraction of their training. This context makes their initial and in-service training all the more problematic. (p. 26)

\subsection{SOUTH AFRICA AS A CASE STUDY FOR STATISTICS EDUCATION}

The issues above are well illustrated and become more concrete when we examine a specific case study. South Africa is a country with over 50 million inhabitants who speak 11 official languages. It includes over 12 million students studying in over 30,000 primary and secondary schools and over 1000 private (independent) schools. The South African educational system employs over 440,000 teachers with varying and sometimes inadequate qualifications, all operating under nine provinces with semi-independent education departments. Further, schools are spread over a very large geographical area (South Africa's total land area is over 1.2 million square kilometers).

As in many other developing countries, the education system in South Africa is in a state of transformation as the government embarks on a process of grappling with legacies of the past, while attempting to restructure education to enhance economic and social progress. In actuality, this means that the South African educational system has had to deal with relatively rapid changes in expectations set for schools and for teachers. A new school curriculum was introduced from 1994 onwards with the goal of allowing all South African youth to receive an education in keeping with the demands of the $21^{\text {st }}$-century (North \& Scheiber, 2011). Yet it became clear that this curriculum was not achieving its intended goals, and national data showed that many students were leaving high-school without getting any exposure to mathematics during their last three years of schooling, or taking and failing mathematics. Hence, since 2003 South Africa has established two separate but related national mathematics curricula at the high-school level, called 'Mathematics' and 'Mathematical Literacy' (Department of Education, 2003a, 2003b), expecting that all school students would do either Mathematics or Mathematical Literacy as part of their last three years of high-school.

The new and unique dual curriculum system, while focused on the high-school level, has ramifications for what needs to be taught in earlier grades and sets different types of expectations from learners and teachers alike. Consequently, it has been the subject of much national discussion and controversy in South Africa (e.g., Christiansen, 2007). Mouton, Louw, and Strydom (2013) have argued that the South African educational system is "flawed, with poorly performing teachers, poor work ethics, lack of community and parental support, poor control by education authorities, poor support for teachers and very low levels of accountability" (p. 1). While such perceptions are open to debate, they cannot be completely dismissed as they are supported by many data sources, including but not limited to the very low performance of South African students in international comparative studies over 20 years. For instance, in TIMSS (Trends in International Mathematics and Science Study) 2011, despite marked improvement in average performance compared to its status in prior TIMSS cycles, South Africa still had the second-lowest mean performance in the world in mathematics, with 
one of the widest score distributions, suggesting very wide variations in skill and knowledge levels across the country (HSRC, 2012).

Putting aside debates regarding South Africa's educational system as a whole, from the point of view of the present paper, South Africa presents a potent case study in which it is possible to examine many aspects of educational transformations typical of developing countries. From the point of view of statistics education, the new 2003 curriculum has paid explicit attention to substantial statistics content, in direct contrast to prior years when very little or no statistics was included (North, Scheiber, \& Ottavianni, 2010). In particular, the establishment of 'Mathematical Literacy' as a nationally-recognized educational focus enables the introduction of many statistical topics and a greater emphasis on the applied or practical aspects of knowing mathematics in general and statistics and probability in particular (Gal, 2009) to many learners who under the previous system would not have had any training in mathematical subjects in their last three years of schooling.

While the introduction of substantial statistics content into the South African curriculum has been seen as essential, and with much potential to change the face of statistical knowledge in South Africa, implementation issues abound (North \& Scheiber, 2011). Among other issues, South Africa still struggles to find enough mathematics teachers and to empower teachers with the basic knowledge to cope with the mathematics content, and changes in content, of the school syllabus (North, Scheiber, \& Ottavianni, 2010). Various studies on teachers in South Africa (e.g., Carnoy \& Chisholm, 2008; UNESCO, 2012), which among other things analyzed both teacher qualifications as well as actual work using a variety of quantitative and qualitative measures, suggest that wide gaps exist between the intended and enacted curriculum in mathematics classes in South Africa. For instance, analyses of videotaped lessons have shown that teachers overemphasize procedural skills and allocate a large proportion of class time to issues or class management practices stemming in part from the large size of classes, in part from teachers' knowledge (e.g., Sorto \& Sapire, 2011).

\section{ANALYSIS OF A FIELD INTERVENTION}

The preceding review implies that the introduction of a relatively new school topic such as statistics into a national curriculum in mathematics can face many challenges in the context of a developing country in general, and in South Africa in particular. This is primarily because of teachers' own knowledge and background. Research (mostly in developed countries) indicates that it is common for teachers to experience difficulty with teaching statistics topics due to lack of relevant knowledge and skills, such as issues regarding content or pedagogy (Stohl, 2005), and lack of prior exposure to, and experience, in this new area. An additional factor that has been identified as affecting teaching performance, however, is teachers' (often negative) attitudes towards statistics (Estrada, Batanero, Fortuny, \& Diaz, 2005; Martins, Nascimento, \& Estrada, 2012). Further, infusion of professional development in statistics education, which is essential given that few teachers have learned statistics or how to teach statistics, is a challenge in a developing country given the many other systemic factors described above, i.e., weak infrastructure, lack of funding and resources for sustaining educational innovation, and anticipated teacher reluctance to try to teach a new topic, etc.

The lack of centralized resources, coupled with a large geographical dispersion and the huge number of schools and teachers involved, required the design of innovative collaborative arrangements which culminated in an initiative called 'KZN maths4stats Lecture Series'. The next section aims to examine selected aspects of the maths4stats initiative rationale and content as they are applied in one province of South Africa, KwaZuluNatal (KZN), which has over 10 million residents in an area of about 91 thousand square kilometers. We then present and reflect on some selected data collected during the program's implementation in order to illustrate some of the many issues involved in developing and studying statistics education in the context of a developing country, and later reflect critically on lessons learned. 


\subsection{CONTEXT AND RATIONALE}

The maths4stats program emerged out of a need to bring basic information about statistics (content knowledge) and about teaching statistics (i.e., pedagogical content knowledge) to relatively large numbers of teachers at a low cost. Further, the intervention also aimed to improve the attitudes toward statistics of in-service teachers who previously had had little or no exposure to statistics, and who work at underperforming schools in rural or less-affluent urban areas in South Africa, and hence may not be motivated to invest in learning a new topic.

The national maths 4stats initiative was launched in 2006 by Statistics South Africa (Stats SA, 2006), the national statistics office, with aim to improve statistics education in South African schools. Stats SA has agreed to provide long-term support in order to address the need for statistics training of mathematics educators. Details of the project can be found in North and Scheiber (2008).

The maths4stats campaign runs independently in each province. Given the lack of any centralized mechanism for teacher training or professional development in the KZN province, and the operational complexities associated with the number and geographical dispersion of schools, in order to facilitate maths4stats in the KZN province, a collaborative arrangement was reached between three partners: University of KwaZulu-Natal (UKZN), Stats SA, and the national Department of Education (DOE). Starting in 2010, the University designed a fiveweekend program, called the KZN maths4stats Lecture Series. Teachers eligible for invitation are identified by the DOE with the criteria for selection being that the school is disadvantaged and in need of improvement. Stats SA handles all matters related to contacting teachers, the registration process, printing materials, and logistics of catering. Materials (course notes) are developed by UKZN statistics lecturers, and workshops are presented voluntarily by UKZN statistics academic staff members, over five weekends, in venues on UKZN campuses. Weekends are used because teachers cannot get released from schools during weekdays, as is the case for statistics lecturers.

Teachers are responsible for their own costs and transport to the program location, many coming from hundreds of kilometers away for each of the five weekends. Since 2010 around 250 teachers have attended each year. The participants are split into three parallel sessions with different foci: GET (General Education and Training) Statistics (grades 1-9), FET (Further Education and Training) Data and Statistics (grades 10-12), and FET Financial Mathematics and Probability (grades 10-12). Materials presented in the program follow a data-driven approach (see the Appendix for an outline), with an emphasis on interpretation and clear communication of findings. Teachers attending the program are each given materials to use in their classroom (such as poker chips, dice, measuring tapes, etc.), as the emphasis is on collecting their own data and then discussing it with other teachers, so that they form a support group for each other. The approach is informal, aiming at self-discovery, with clear guidance from the statistics lecturer presenting the materials. Teachers go systematically through all of the statistics topics in the school curriculum, over the five-weekend duration of the program.

Due to DOE regulations, teachers are asked to take a written test at the end of the last meeting of the program. The test is taken on an optional basis, with a 'mystery prize' being promised to each participant that scores over $60 \%$ on the assessment, as an incentive for attendance and learning at the five-weekend program. The program concludes with an awards day, consisting of three workshops (Casio calculator workshop, Stats SA CensusAtSchool demonstration, and SAS Curriculum Pathways demonstration) followed by the awarding of certificates of attendance for teachers who participated in all lessons and certificates of proficiency (plus a 'mystery prize') for teachers who achieved over $60 \%$ in the assessment.

\subsection{REFLECTIONS ON THE DESIGN OF THE INTERVENTION PROGRAM}

In designing the KZN maths4stats program, it was necessary to consider that the teaching force in South Africa includes many teachers who may be teaching mathematics, but who lack suitable qualifications in the subject (Howie, 2003). Since teachers' familiarity with statistics is at best superficial, a primary goal of the intervention was not to impart specific teaching 
techniques, but rather to improve teachers' familiarity with statistics as a domain of social action and as an instructional topic, helping to promote a higher level of confidence in teaching statistics topics in the classroom. The logistics of a workshop session, in which many teachers convene for a few hours for several weekends, inhibits practical learning of actual methods of teaching statistics by the attendees, and time is sufficient only for simple demonstrations of lesson plans that teachers could try on their own in their classrooms.

The structure of the program was constrained by factors such as timing and amount of available time. The training materials had to take into account the fact that teachers come from a multi-lingual setting (11 official languages), have varying levels of mathematical preparedness, and may have had no training in statistics (North \& Scheiber, 2008). An important aim of setting up the program was to find a sustainable structure that can continue over time rather than be a one-off intervention.

The identification of teachers to attend the workshop is left to DOE officials, who bring in both Mathematics and Mathematical Literacy teachers from disadvantaged or under-performing schools. Thus, the results can highlight the experience of teachers from schools which exhibit the most need. Though the intervention focuses on teachers with particular backgrounds, it does not mean that the program is appropriate only for such groups, or that its structure cannot change over time.

The ongoing success of the program depends on the continued common understanding and vision of the university statistics lecturers, the government education department, and the official statistics agency, who all play a key role. The challenge is to maintain the continued commitment of all three parties, together with administrative support that helps them to work together synergistically.

\subsection{RESEARCH OPPORTUNITIES WITHIN AN INTERVENTION PROGRAM}

Three related but separate factors emerged during the program design and planning which had implications for research opportunities or directions:

- Time: The need in the field is to maximize the use of the limited time that participating teachers volunteer for attending the program. Thus, any minute taken out of the lecture series in order to have teachers complete research surveys has to be carefully designed and justified, and teachers have to agree to participate.

- Languages: Most teachers operate in a multilingual situation, i.e., their home language is not English, yet they attend a lecture series given in English and if the organizers choose to administer any questionnaires, the respondents have to cope with an instrument written in a language with which they may not be fully fluent. This also constrains the type of data that can be collected from participants.

- Budgets and institutional support: No budget was officially made available for program evaluation or for follow-up on how teachers implement what they have studied. Further, representatives of the sponsoring agencies (Stats SA, DOE) did not express a need to conduct research or collect long-term data. It seems that this was due to the sense of urgency in launching the program and maximizing the instructional time within it.

With these considerations in mind, we managed to design a simple questionnaire in order to evaluate the intervention in terms of teachers' confidence and attitude toward teaching statistics. The questionnaire was piloted with the 2012 participating teachers, both before they attended the first lesson in the workshop series, and again at the end of the fifth (final) session. The questionnaire aimed to get an insight into the effect of the workshop series on teacher attitudes, seen as underlying (or hindering) further work they may choose to undertake with regard to statistics teaching.

We were fully aware of the availability of several established research instruments for assessment of attitudes towards statistics, in part given our prior work in that area (e.g., Gal, Ginsburg, \& Schau, 1997). Yet, we deemed existing instruments too complex for use in the South African context, as they are lengthy and some of their items involve nuances that could be confusing in a multilingual context. Instead, we opted for a survey that takes into account the 
constraints described above. Teachers were asked to rate their level of confidence in teaching data handling (statistics) topics using a simple Likert rating scale with four levels ('poor', 'moderate', 'good', 'excellent'). Additional questions were presented at the end of the workshop, including one regarding teachers' confidence in their students' ease of learning the statistical materials covered in the workshop, using three levels: 'with ease', 'slight difficulty', and 'will never cope'. The scales in both questionnaires were designed to be short and simple in order to combat language barriers and to simplify administration, explanations, and analysis.

Figure 1 presents the data about teachers' confidence in teaching statistics before and after the five-lesson workshop series; Table 1 shows the raw data regarding their rating of confidence. Figure 1 highlights the positive shift in teachers' ratings. For instance, the majority (93\%) of the 28 teachers who initially judged their confidence to be poor improved their rating to 'good' or 'excellent' at the end. Higher along the scale, most of the teachers who initially felt that their confidence to teach statistics topics was good, still continued to come to the lessons over five weekends, and $81 \%$ of them increased their rating of confidence to 'excellent' after the intervention.

Table 1. Teachers' ratings of confidence in teaching statistics, before and after a workshop

\begin{tabular}{cccccr}
\hline & \multicolumn{5}{c}{ After } \\
\cline { 2 - 6 } Before & Poor & Moderate & Good & Excellent & Total \\
\hline Poor & 1 & 1 & 17 & 9 & 28 \\
Moderate & 0 & 3 & 51 & 74 & 128 \\
Good & 0 & 0 & 15 & 63 & 78 \\
Excellent & 0 & 0 & 3 & 15 & 18 \\
\hline Total & 1 & 4 & 86 & 161 & 252 \\
\hline
\end{tabular}

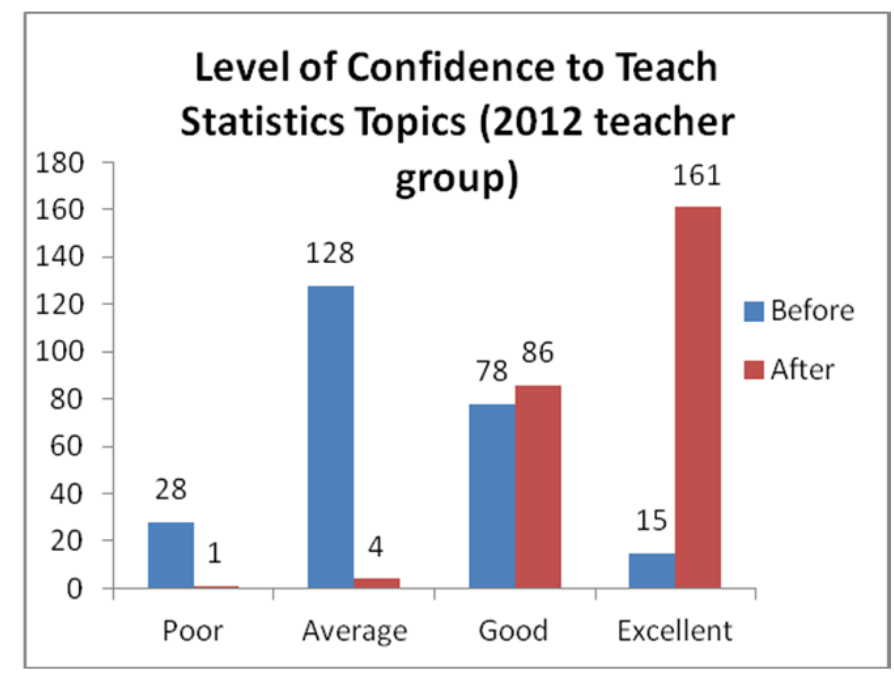

Figure 1. Teachers' confidence in teaching statistics, before and after workshop

Participants were further asked to rate at the end of the workshop, how they feel a typical learner in their class would handle topics covered in the program. The majority of teachers $(65 \%)$ perceived that students could learn the material 'with ease', and only $3 \%$ anticipated that their students would not be able to cope.

Table 2 shows a cross-tabulation of teachers' change in teaching confidence (measured in terms of the change in their level, so 'poor' to 'moderate' is represented by +1 up) and their views of students' ability to learn the material. The results show that in each category of confidence gain, most teachers felt that learners would manage the material with ease. 
Table 2. Teachers' gain in confidence in teaching statistics, and confidence in students' ability to learn

\begin{tabular}{|c|c|c|c|c|}
\hline \multirow[b]{2}{*}{$\begin{array}{l}\text { Change in level of } \\
\text { confidence to teach }\end{array}$} & \multicolumn{3}{|c|}{ Confidence in students' ability to learn: } & \multirow[b]{2}{*}{ Tota } \\
\hline & With ease & $\begin{array}{c}\text { Slight } \\
\text { difficulty }\end{array}$ & $\begin{array}{l}\text { Will never } \\
\text { cope }\end{array}$ & \\
\hline-1 & 3 & 0 & 0 & 3 \\
\hline 0 & 21 & 12 & 1 & 34 \\
\hline+1 & 65 & 43 & 4 & 112 \\
\hline+2 & 66 & 23 & 2 & 91 \\
\hline+3 & 8 & 1 & 0 & 9 \\
\hline Total & 163 & 79 & 7 & 249 \\
\hline
\end{tabular}

It is worth noting that among teachers who gained confidence, the more the teachers gained in confidence as a result of the workshop, the more they were inclined to say that learners would handle the material with ease. This is an indication that the small intervention gave them a gain in confidence to teach, and increased their perception that learners could master the statistics topics discussed.

\section{CONCLUSION}

Most existing literature on ways to improve statistics learning focuses on in-class topics, such as teaching methods, students' cognitions, or students' attitudes. While all these factors are important and at the heart of the statistics education enterprise, this paper argues that the notion of capacity-building in the area of statistics education is a complex undertaking when viewed in the context of a developing country. Using South Africa as a case study, the paper has aimed to illustrate the complex and multi-faceted nature of capacity building in such a country.

The KZN maths4stats program design, by itself, offers a potent example for a new kind of a collaborative arrangement between three partners (a university, a ministerial department, and an official statistics agency). It shows that it is possible, and in fact essential, to build an intervention that benefits from the strengths, capacities, and institutional needs and goals of all partners, as well as pools funding and resources to make it sustainable. However, such a program does not emerge by itself, and substantial discussions (and some trial and error) were needed in order to find a format that is reasonable not only for the partners, but also for the teachers who are expected to make a substantial investment of time, energy, and personal funds in a topic with which they have little familiarity.

In our view, it is not sufficient to examine, for example, the processes within a single classroom or the learning trajectory of a few students, as interesting as such studies may be. It is necessary to look also at the broader ecology within which instruction takes place, or could emerge, in order to understand more fully where and how capacity in statistics education can be developed, and what factors affect learning outcomes.

With such a context as a backdrop, the role of 'learning lessons from a simple intervention' has to be carefully unpacked and reconsidered so as to inform future endeavors. In the context of a developing country, additional challenges and barriers to teacher training include:

- shortage of funds

- lack of organizational and logistical infrastructure to disseminate information about the new school topic (i.e., statistics)

- logistical problems related to training large numbers of teachers who are distributed over a wide geographical area

- varying levels of infrastructure at schools

- varying levels of preparedness and awareness of statistics amongst teachers 
- varying conceptions among statistics instructors (who run the workshops) of what is required of teachers in schools, versus what teachers can actually implement in a classroom setting

- the extent to which textbooks exist written in such a way that they can help teachers design lessons and adapt them to the needs of students with different levels of skills

Many factors affect the ability of teachers to teach statistical topics in a way that improves statistical knowledge or statistical literacy of learners. Examples are teachers' background, their self-efficacy (confidence), appreciation for the value of statistics, their knowledge of the subject matter (pedagogical content knowledge), etc. Affective and attitudinal factors in particular are likely to become important during a class, once students begin to experience difficulties or frustrations with their statistics studies (Gal, Ginsberg, \& Schau, 1997). Though much research has been done in the area of statistics attitudes (Hilton, Schau, \& Olsen, 2004), it is rare to see research in a developing country on the ability of an intervention to impact positively on statistical attitudes.

As noted earlier, it was evident from the outset that the attitude/confidence survey designed for the present program does not permit the analytic power afforded by established instruments in the field (for one recent review, see Ramirez, Schau, \& Emmioğlu, 2012). However, despite its simplicity, the survey was able to detect changes in participants' attitudes, was answered by virtually all participants, and hence offered a good cost-to-benefit ratio in terms of the time and resources available for its administration, coding, and analysis, in a field context.

The lessons learned from such a collaborative project between a university, a government education department and the government statistics office seem to point to an improvement in teachers' confidence to teach statistics, as well as a growth in their confidence that learners are able to understand the statistics topics in the school curriculum. In other words, the intervention has demonstrated the potential for improved teaching of statistics by these teachers who have completed the workshop series. These data are encouraging in terms of the evidence they provide for the possibility that the intervention program is leading to results which are consistent with one of its goals. That said, the data we collected were limited by various operational constraints that affect the design of the survey, and so should be viewed with caution. It will take further research to demonstrate the effect of such an intervention on teachers' actual teaching of statistics and students' learning of the topics discussed.

Further, an analysis of program effectiveness in the context of a developing country has to take into account the distinctive goals and constraints of in-service training and the threshold level of interest of the participants. A concerted, multi-workshop series has to be designed in advance and spread over time, in order to be able not only to present relevant information, but also to examine its effectiveness with participants, allowing them to share their own instructional experiences. A proper program evaluation module has to be designed in advance. It will involve not only a summative evaluation regarding changes in knowledge and attitudes, but also a formative evaluation component that looks at barriers and blocking factors regarding teachers' initial interest and willingness to participate, actual participation patterns, postworkshop behaviors (e.g., did teachers implement any of the ideas in the workshop, and if so, how and when) and their underlying causes, and so forth. That said, the fact that teachers came to workshops, week after week, at their own cost and often travelling long distances, is an indication of teachers' impressions of positive impact of the lessons on their ability to teach statistics.

Finally, it is important to reflect on the contextual constraints and the factors that affect the design and working process of the math4stats program, and their implications for the future of in-service workshops aiming to improve statistics education in South Africa and other developing countries, and for future research. The present content of the workshop is focused mainly on procedural or formal aspects of statistics and probability, with relatively little attention to interpretation and communication, or with understanding of real-world (e.g., mediabased) statistical messages. This situation stems from multiple factors, i.e., the curriculum specification in South Africa and expectations of the Department of Education, the weak background of many teachers with the mathematics that underlie basic statistical procedures, and teachers' relatively low confidence. In addition, the linguistic diversity among teachers and 
students alike is such that attention to interpretation and communication, and development of critical discussion of statistical messages, are difficult to carry out in the current program format.

Further program time and additional resources are also needed in order to introduce aspects of statistical literacy into the program, yet such time is not available, nor is it possible to involve teachers in small-group work or in extended open-ended discussions given the large numbers of teachers that sit together in the workshops. Addressing such issues is a challenge in a developing country and will require the introduction of new and longer interventions with different formats, additional funding, and the support of further research. In parallel, research on the impact or effectiveness of such extensions will require the development of assessment instruments which can double as research instruments, so as to reduce the burden on participating teachers' time.

In closing, we note that our cumulative experience suggests that the lack of resources and the practical limitations on participation must be taken into account in designing more effective interventions. Alternative modes of delivery have to be examined, maybe a 'travelling trainer' or maybe distance education methods such as internet-based lectures or demonstration videos provided on DVD, still available in remote areas. Even the lack of electricity at some schools could be overcome by offering online lessons and demonstrations to teachers at community centers where internet access is available.

Despite the problems associated with merging a research component into an operational field program, we believe that such efforts are very relevant. The introduction of statistics into the school curriculum in South Africa and other countries provided an opportunity for laying the foundation for much needed capacity-building. There is a need to develop the statistical literacy of school leavers so that they can better orient themselves in a data-driven society. In addition, it is essential to increase awareness of the possibility of studying statistics as career at tertiary and professional levels. A review of the status of mathematical sciences in South Africa (Department of Science and Technology, 2008) has argued that "the status of statistics is at a stage that is so critical that the field is in danger of disappearing through lack of academic capacity, with the closure of academic departments being a real possibility." The report goes on to offer many recommendations, one being to "broaden the base", i.e. to get more school leavers interested in studying statistics at post-school level. Hence, there is a need to teach statistics topics in a way that excites both schoolchildren and their teachers about the discipline, and to develop simple inexpensive research strategies that can enable a valid examination of the impact of such interventions within the constraints existing in developing countries.

\section{REFERENCES}

Carnoy, M., Chisholm, L., et al. (2008). Towards Understanding Student Academic Performance in South Africa: A Pilot Study of Grade 6 Mathematics Lessons in South Africa. Pretoria: Human Sciences Research Council.

Christiansen, I. M. (2007). Mathematical Literacy as a school subject: Mathematical gaze or livelihood gaze? African Journal of Research in Mathematics, Science and Technology Education, 11(1), 91-105.

Department of Education (2003a). National Curriculum Statement Grades 10-12: Mathematics. Pretoria: Department of Education.

[Online: http://www.education.gov.za/curriculum/subjectstatements.asp ]

Department of Education (2003b). National Curriculum Statement Grades 10-12: Mathematical Literacy. Pretoria: Department of Education.

[Online: http://www.education.gov.za/curriculum/subjectstatements.asp ]

Department of Science and Technology (2008). The International Review Panel Report on the Review of Mathematical Sciences Research at South African Higher Education Institutions (18.12.2008).

[Online: http://www.nrf.ac.za/files/file/Report.pdf ] 
Estrada, A., Batanero, C., Fortuny, J. M., \& Díaz, C. (2005). A structural study of future teachers' attitudes towards statistics. In Proceedings of the 4th Congress of the European Society for Research in Mathematics Education (pp. 508-517).

Gal, I. (2009). South Africa's mathematical literacy and mathematics curricula: is probability literacy given a fair chance? African Journal of Research in Mathematics, Science, and Technology Education, 13(1), 50-61.

Gal, I., Ginsburg, L., \& Schau, C. (1997). Monitoring attitudes and beliefs in statistics education. In I. Gal \& J. B. Garfield (Eds.), The assessment challenge in statistics education (pp. 37-51). Amsterdam: IOS Press.

Glewwe, P. \& Kremer, M. (2005). Schools, teachers, and education outcomes in developing countries. In E. A. Hanushek, S. Machin \& L. Woessmann (Eds.), Handbook of the economics of education vol. 2 (pp. 945-1017). Amsterdam: Elsevier.

Glewwe, P., Hanushek, E. A., Humpage, S. D., \& Ravina, R. (2011). School Resources and Educational Outcomes in Developing Countries: A review of the literature from 1990 to 2010 (NBER Working Paper No. 17554). Massachusetts: National Bureau of Economic Research.

[Online: http://www.nber.org/papers/w17554.pdf?new_window=1]

Hilton, S. C., Schau, C., \& Olsen, J. A. (2004). Survey of Attitudes Toward Statistics: Factor structure invariance by gender and by administration time. Structural Equation Modelling, 11(1), 92-109.

Howie, S. (2003). Language and other Background Factors Affecting Secondary Pupils' Performance in Mathematics in South Africa. [Online: http://hdl.handle.net/2263/4915 ]

HSRC (2012). Highlights from TIMSS 2011: The South African perspective. Pretoria: Human Sciences Research Council.

[Online: http://www.hsrc.ac.za/uploads/pageContent/2929/TIMSSHighlights2012Dec7final.pdf ]

Martins, J. A., Nascimento, M. M., \& Estrada, A. (2012). Looking back over their shoulders: a qualitative analysis of Portuguese teachers' attitudes towards statistics. Statistics Education Research Journal, 11(2), 26-44.

[ Online: http://iase-web.org/documents/SERJ/SERJ11(2) Martins.pdf ]

Mouton, N., Louw, G. P., \& Strydom, G. (2013). Critical challenges of the South African school system. International Business \& Economics Research Journal, 12(1), 31-44.

North, D., \& Scheiber, J. (2008). Introducing statistics at school level in South Africa: The crucial role played by the national statistics office in training in-service teachers. ICMI Study and IASE Roundtable Proceedings.

[Online: http://www.ugr.es/ icmi/iase study/ ]

North, D., \& Scheiber, J. (2011). The role of statistical offices and associations in supporting the teaching of statistics at school level. Teaching Statistics in School Mathematics Challenges for teaching and teacher education (pp. 395-406). Netherlands: Springer.

North, D., Scheiber, J., \& Ottaviani, G. M. (2010). Training teachers to teach statistics in South Africa: Realities and attitudes. In C. Reading (Ed.), Data and Context in Statistics Education: Towards an evidence-based society. Proceedings of the 8th International Conference on Teaching Statistics, Ljubljana, Slovenia.

[Online: http://iase-web.org/documents/papers/icots8/ICOTS8 10C2 NORTH.pdf]

Ramirez, C., Schau, C. \& Emmioğlu, E. (2012). The importance of attitudes in statistics education. Statistics Education Research Journal, 11(2), 57-71. [Online: http://iase-web.org/documents/SERJ/SERJ11(2)_Ramirez.pdf ]

Sorto, M. A., \& Sapire, I. (2011). The teaching quality of mathematics lessons in South African schools. Journal of Education, 51, 1-22.

Statistics South Africa (Stats SA) (2006). Maths4stats: Towards a nation that counts. [Online: http://unesdoc.unesco.org/images/0019/001917/191776e.pdf ]

Stohl, H. (2005). Probability in teacher education and development. In G. Jones (Ed.), Exploring probability in school (pp. 345-366). New York: Springer.

UNESCO (2012). Challenges in Basic Mathematics Education. Paris, France.

[Online: http://unesdoc.unesco.org/images/0019/001917/191776e.pdf ] 
UNESCO (2014). Education For All Global Monitoring Report - Teaching and Learning. Paris, France.

[Online: http://unesdoc.unesco.org/images/0022/002256/225654e.pdf ]

Zewotir, T., \& North, D. (2011). Opportunities and challenges for statistics education in South Africa. Pythagoras, 32(2).

[Online: http//dx.doi./org/10.4102/pythagoras.v32/2.28 ]

DELIA NORTH

University of KwaZulu-Natal, South Africa

P.O. Box X54001

Durban 3630

South Africa 


\begin{abstract}
APPENDIX
The GET (General Education and Training) Phase Data Lessons comprise the following topics: collecting and sorting data (data types, surveys, questionnaires, populations, samples, tally tables, frequency); displaying data (pictograms, bar graphs, stem-and leaf plots, compound \& sectional bar graphs, pie graphs, graphs for grouped discrete data; choosing the most appropriate graph); analysis of discrete data (mean, median, mode, range).

In the FET (Further Education and Training) phase these topics are presented at a higher cognitive level, with the further extension of working with continuous data, so that additional topics are added: grouping then analyzing continuous data (mean, median, mode, range, variance and standard deviation of grouped data), quartiles, interquartile range, outliers, boxand-whisker plots, regression and correlation, recognizing Normal distributions by interrogating the symmetry and proportion of values within one standard deviation of the mean.

The GET Phase Lessons on Probability deal with the concept of certainty and uncertainty, frequency, relative frequency of outcomes of a random experiment; events, classical definition of probability, calculating probabilities using tree diagrams). In the FET phase, these topics are similarly presented at a higher cognitive level and further topics are added which include: basic set theory, Venn diagrams, mutually exclusive events, dependent and independent events; conditional probability; calculating probabilities and conditional probabilities from two-way contingency tables, counting rules, problem solving using probability rules.
\end{abstract}

